\title{
INTRACAMERAL AND INTRACORNEAL VORICONAZOLE IN DEEP KERATOMYCOSIS WITH ENDOTHELIAL PLAQUE
}

\author{
Srinivas Prasad Killani' ${ }^{1}$,Srihari Atti², Atul Gupta ${ }^{3}$, Sambasiva Reddy Pujala4, Sridhar Goli ${ }^{5}$, Superna Mahendra ${ }^{6}$, Archana Adapala ${ }^{7}$, \\ Kranthi Budamakayala ${ }^{8}$
}

\begin{abstract}
${ }^{1}$ Assistant Professor, Department of Ophthalmology, Osmania Medical College, Sarojini Devi Eye Hospital, Hyderabad, Telangana. ${ }^{2}$ Associate Professor, Department of Ophthalmology, Osmania Medical College, Sarojini Devi Eye Hospital, Hyderabad, Telangana. ${ }^{3}$ Assistant Professor, Department of Ophthalmology, Osmania Medical College, Sarojini Devi Eye Hospital, Hyderabad, Telangana. ${ }^{4}$ Assistant Professor, Department of Ophthalmology, Osmania Medical College, Sarojini Devi Eye Hospital, Hyderabad, Telangana. ${ }^{5}$ Assistant Professor, Department of Ophthalmology, Osmania Medical College, Sarojini Devi Eye Hospital, Hyderabad, Telangana. ${ }^{6}$ Assistant Professor, Department of Ophthalmology, Osmania Medical College, Sarojini Devi Eye Hospital, Hyderabad, Telangana. ${ }^{7}$ Post Graduate, Department of Ophthalmology, Osmania Medical College, Sarojini Devi Eye Hospital, Hyderabad, Telangana. ${ }^{8}$ Post Graduate, Department of Ophthalmology, Osmania Medical College, Sarojini Devi Eye Hospital, Hyderabad, Telangana.
\end{abstract}

\section{ABSTRACT}

Fungal keratitis, one of the major causes of ophthalmic mycosis is second only to cataract as the most common cause of blindness worldwide.

\section{OBJECTIVE}

The aim was to study the intracorneal and intracameral Voriconazole in deep keratomycosis with endothelial plaque.

\section{MATERIALS AND METHODS}

This was a study in the Cornea Clinic of Sarojini Devi Eye Hospital and Regional Institute of Ophthalmology, a Tertiary Care Teaching Hospital of Osmania Medical College (Govt.), Hyderabad, over a period from September 2012 to August 2014. The study group included 30 patients who were diagnosed clinically and microbiologically (+ve smear and culture) as fungal corneal ulcers with deep stromal infiltrates and endothelial plaque not responding to routine antifungal drugs and given voriconazole intracorneally and intracamerally.

Data of patient's age and sex and history of corneal trauma with type of the agents were noted. The time of healing of the ulcer with the scar formation after intracorneal and intracameral voriconazole was noted and the visual acuity was recorded after the healing of the corneal ulcer.

\section{RESULTS}

Thirty eyes of 30 patients with deep keratomycosis with endothelial plaque were evaluated; $19(63.3 \%)$ were Males and $11(36.7 \%)$ were Females. Age distribution was $4(13.3 \%)$ in $>10-20$ Yrs, 5(16.7\%) in 21-30 Yrs, 4(13.3\%) in 31-40 Yrs, 6(20.0\%) in 41-50 Yrs, 5(16.7\%) in 51-60 Yrs and 6(20.0\%) in 61-70 Yrs. The type of trauma was the organic (Vegetative matter) in $19(63.4 \%)$, inorganic matter in $8(26.7 \%)$ and no H/o trauma with the agent not known in $3(10.0 \%)$. The causative fungi were Fusarium in 15(50.0\%), Aspergillus in 12(40.0\%) and Candida in 3(10.0). The time of healing of the Fungal Corneal Ulcer after Intracorneal and Intracameral Voriconazole was 4(13.3\%) in 4-6 wks.; 12 (40.0\%) in 6-8 wks., 5(16.7\%) in 8-10 wks., and $4(13.3 \%)$ in 10-12 wks.; $25(83.3 \%)$ which were healed by corneal scarring were given 1 (One) intracorneal and intracameral injection of Voriconazole. The $5(16.7 \%$ ) did not respond to 2 (Two) intracorneal and intracameral voriconazole injections, progressed to corneal perforations and were treated by Therapeutic Penetrating keratoplasty. Visual acuity was <3/60 in $18(60.0 \%)$ and $3 / 60$ to $<6 / 60$ in $12(40.0 \%)$, and $<3 / 60$ in $3(10.0 \%), 3 / 60-<6 / 60$ in $13(43.3 \%)$ and $6 / 60-<6 / 18$ in $9(30.0 \%)$ before and after the intracorneal and intracameral voriconazole respectively.

\section{CONCLUSIONS}

Targeted delivery of Intracorneal and Intracameral Voriconazole was effective with a better visual outcome and a significant reduction in healing time in deep keratomycosis with endothelial plaque not responding to routine antifungal therapy.

\section{KEYWORDS}

Deep Keratomycosis, Endothelial Plaque, Voriconazole, Intracorneal, Intracameral.

HOW TO CITE THIS ARTICLE: Srinivas Prasad Killani, Srihari Atti, Atul Gupta, Sambasiva Reddy Pujala, Sridhar Goli, Superna Mahendra, Archana Adapala, Kranthi Budamakayala. "Intracameral and Intracorneal Voriconazole in Deep Keratomycosis with Endothelial Plaque." Journal of Evolution of Medical and Dental Sciences 2015; Vol. 4, Issue 99, December 10; Page: 16476-16480, DOI: $10.14260 /$ jemds/2015/2446

\section{INTRODUCTION}

Ocular fungal infections or ophthalmic mycoses are common, especially in tropical countries with a poor prognosis compared to bacterial infections.

Financial or Other, Competing Interest: None.

Submission 20-11-2015, Peer Review 21-11-2015,

Acceptance 02-12-2015, Published 10-12-2015.

Corresponding Author:

Dr. Srinivas Prasad Killani,

Srihari Atti, Cornea Clinic,

Sarojini Devi Eye Hospital,

Hyderabad-500028, Telangana, India.

E-mail:drkillani@gmail.com,srihariatti@gmail.com

DOI:10.14260/jemds/2015/2446
Corneal disease is second only to cataract as the most common cause of blindness worldwide with more than 1.5 million new cases of vision loss yearly. $(1,2)$

It is a leading cause of monocular blindness worldwide accounting for about $50 \%$ of all cases of infectious keratitis in developing countries.(2) Predisposing factors to the fungal infection are trauma with organic matter, long-term use of antibiotics and steroids, corneal surface disorders, refractive surgeries and contact lens disinfectant solutions.(3) Fungi can invade Corneal stromal lamella, penetrate an intact Descemet's membrane and spread into the anterior chamber. The toxicity of fungus is related to its mycotoxin and its ability to replicate. Fungal keratitis is usually characterized by a corneal epithelial defect and inflammation of the corneal 
stroma with endothelial plaque, hypopyon, fungal web and fungal ball in the anterior chamber. If untreated, fungal keratitis can lead to corneal scarring and vision loss.

Corneal infections involving the deeper parts of the stroma are not amenable to routine topical antifungal therapy. The currently available antifungal agents, amphotericin B, natamycin, fluconazole, ketoconazole, 5flucytosine, itraconazole and voriconazole have limitations of poor penetration into the eye, limited spectrum of activity and surface toxicity. $(4,5)$ Surgical intervention in the form of therapeutic keratoplasty is required more often in fungal keratitis compared with bacterial keratitis indicating a poor response to treatment with antifungal agents. To overcome these problems, alternate routes were evaluated in fungal keratitis like intracorneal, intracameral, intravitreal, etc. Intracorneal and intracameral injections of amphotericin B. $(6,7,8,9)$ and Intracameral Amphotericin-B.(6,8) were tried in fungal keratitis. But Amphotercin was associated with increased anterior chamber reactions and the risk of potential injury to the lens and toxicity to the corneal endothelium.

Marangon FB, et al.(10) conducted a study to investigate the in vitro efficacy of voriconazole and other antifungals. Lalitha $\mathrm{P}$, et al.(11) studies have suggested that voriconazole may have a broader spectrum of antifungal activity compared with amphotericin B. Gao H, et al.(12) and Nehemy MB, et al.(13) have reported intraocular voriconazole to be safe in vitro and in vivo and less toxic to retina than amphotericin $B$.

Voriconazole, a recent azole antifungal acts by inhibiting the synthesis of ergosterol in the fungal membranes and ultimately the growth of the microrganism. Voriconazole has a superior activity against fungi that are resistant to amphotericin $\mathrm{B}$ and itraconazole. It also has a good safety profile. It is available in the form of oral and IV formulations. Oral voriconazole is highly bio-available (96\%) and has demonstrated good penetration into different parts of the eye. However, oral voriconazole can be associated with side effects as well as significant drug interactions. Topical $1 \%$ voriconazole demonstrated a good penetration through the cornea into aqueous humour without compromising intraocular safety. The intracorneal and intracameral voriconazole help in resolution of the ulcer with no adverse effects and facilitate the clearance of the nidus of infection from cornea. $(4,5)$ Voriconazole $50 \mu \mathrm{g} / 0.1 \mathrm{ml}$ is used to inject circumferentially around the fungal abscess in the corneal stroma and in the anterior chamber as an adjunctive to topical antifungal therapy.

\section{AIM}

The aim was to study the intracorneal and intracameral Voriconazole in deep keratomycosis with endothelial plaque.

\section{MATERIALS AND METHODS}

This was a study in the Cornea Clinic of Sarojini Devi Eye Hospital and Regional Institute of Ophthalmology, a Tertiary Care Teaching Hospital of Osmania Medical College (Govt.) Hyderabad over a period from September 2012 to August 2014. The study group included 30 patients who were diagnosed clinically and microbiologically (+ve smear and culture) as fungal corneal ulcers with deep stromal infiltrates and endothelial plaque not responding to routine antifungal drugs and given voriconazole intracorneally and intracamerally. The patients with perforated fungal corneal ulcers and children $<10$ yrs. age were excluded. The study was approved by the Institute of Ethical Committee with the informed consent from all the patients of the study group.
Data of patient's age and sex and history of corneal trauma with type of the agents were noted. Each patient underwent a detailed clinical evaluation of recording the medical history, Snellen's visual acuity testing, slit-lamp biomicroscopy and ultrasonography to evaluate the posterior segment. Corneal scrapings obtained under topical anaesthesia were sent for microbiological investigations of Potassium Hydroxide (KOH) wet-mount preparation, Gram's stain and cultures on blood agar, chocolate agar and Sabaroud's agar.

Once the fungus was +ve for $\mathrm{KOH}$ and Gram stains, topical drops of $5 \%$ natamycin and $1 \%$ voriconazole eye drops every 2 hours, drops of $1 \%$ cyclopentolate hydrochloride 3 times a day and Tablet Itraconazole $100 \mathrm{mg} 2$ times per day were given. When the clinical response was not seen in 2 to 3 weeks or the ulcer showed the signs of worsening, all the patients were given Voriconazole 50 micrograms in $0.1 \mathrm{ml}$ intracorneally as a barrage circumferentially around the fungal abscess and 50 micrograms in $0.1 \mathrm{ml}$ intracamerally under sterile techniques. The anterior chamber was washed thoroughly after 60 seconds contact time of intracameral voriconazole. Second injection was given when no clinical response was found after a minimum of 48 hours duration after the first injection. Totally not more than two injections of intracorneal and intracameral voriconazole were given.

Topical and systemic antifungal drugs were continued even after starting intracameral and intracorneal voriconazole injections. The topical antifungal was given for at least one week after the complete resolution of the infection. The infection was considered resolved when there was a complete healing of the ulcer with scar formation. If the patient was showing signs of worsening or if the ulcer or endothelial plaque was rapidly worsening after intracorneal and intracameral voriconazole injections, Therapeutic Penetrating Keratoplasty (TKP) was done. The time of healing of the ulcer with the scar formation after intracorneal and intracameral voriconazole was noted and the visual acuity was recorded after the healing of the corneal ulcer. The ulcer was defined as not improved if there was no change in the size of the ulcer and worsened if there was an increase in size or depth of ulcer or perforation. All the data was analyzed by simple statistical methods.

\section{RESULTS}

Thirty eyes of 30 patients with deep keratomycosis with endothelial plaque were evaluated after the intracorneal and intracameral voriconazole injection.

\begin{tabular}{|c|c|c|c|c|c|}
\hline Sl. No & Age Group & Males & Females & Total & $\%$ \\
\hline 1. & $10-20$ & 4 & 0 & 4 & 13.3 \\
\hline 2. & $21-30$ & 2 & 3 & 5 & 16.7 \\
\hline 3. & $31-40$ & 1 & 3 & 4 & 13.3 \\
\hline 4. & $41-50$ & 3 & 3 & 6 & 20.0 \\
\hline 5. & $51-60$ & 3 & 2 & 5 & 16.7 \\
\hline 6. & $61-70$ & 6 & 0 & 6 & 20.0 \\
\hline \multicolumn{2}{|r|}{ Total } & 19 & 11 & 30 & 100.0 \\
\hline & $\%$ & 63.3 & 36.7 & & \\
\hline \multicolumn{6}{|c|}{ Table 1: Age group and Gender } \\
\hline
\end{tabular}

Sex distribution was 19(63.3\%) Males and 11(36.7\%) Females. Age distribution was $4(13.3 \%)$ in $>10-20$ yrs, $5(16.7 \%)$ in $21-30 \mathrm{yrs}, 4(13.3 \%)$ in $31-40 \mathrm{yrs}, 6(20.0 \%)$ in $41-50 \mathrm{yrs}, 5(16.7 \%)$ in $51-60 \mathrm{yrs}$, and $6(20.0 \%)$ in $61-70 \mathrm{yrs}$. 


\begin{tabular}{|c|c|c|c|c|}
\hline $\begin{array}{l}\text { Sl. } \\
\text { No. }\end{array}$ & $\begin{array}{l}\text { Type of } \\
\text { Trauma }\end{array}$ & Type of Agent & $\begin{array}{l}\text { No. of } \\
\text { Cases }\end{array}$ & $\%$ \\
\hline \multirow{6}{*}{1.} & \multirow{6}{*}{$\begin{array}{c}\text { Organic } \\
\text { (Vegetative) }\end{array}$} & & 19 & 63.4 \\
\hline & & Paddy Husk & 9 & 30.0 \\
\hline & & Thorns & 4 & 13.3 \\
\hline & & Leaves & 2 & 6.7 \\
\hline & & Insects & 2 & 6.7 \\
\hline & & Animal Tail & 2 & 6.7 \\
\hline \multirow{4}{*}{2.} & \multirow{4}{*}{ Inorganic } & & 8 & 26.7 \\
\hline & & Stone & 2 & 6.7 \\
\hline & & Sand & 4 & 13.3 \\
\hline & & Foreign Body & 2 & 6.7 \\
\hline \multirow[t]{2}{*}{3.} & $\begin{array}{l}\text { No H/o } \\
\text { Trauma }\end{array}$ & $\begin{array}{l}\text { Agent not } \\
\text { Known }\end{array}$ & 3 & 10.0 \\
\hline & \multicolumn{2}{|c|}{ Total } & 30 & 100.0 \\
\hline
\end{tabular}

The type of the trauma was the organic (Vegetative matter) in $19(63.4 \%)$, inorganic matter in $8(26.7 \%)$ and no H/o Trauma with the agent not known in $3(10.0 \%)$.

\begin{tabular}{|c|c|c|c|c|c|}
\hline $\begin{array}{l}\text { Sl. } \\
\text { No }\end{array}$ & $\begin{array}{l}\text { Type of } \\
\text { Fungus }\end{array}$ & Males & Females & Total & $\%$ \\
\hline 1. & $\begin{array}{c}\text { Fusarium } \\
\text { species }\end{array}$ & 7 & 8 & 15 & 50.0 \\
\hline 2. & $\begin{array}{l}\text { Aspergillus } \\
\text { species }\end{array}$ & 7 & 5 & 12 & 40.0 \\
\hline 3. & Candida species & 3 & 0 & 3 & 10.0 \\
\hline \multicolumn{2}{|r|}{ Total } & 17 & 13 & 30 & 100.0 \\
\hline \multicolumn{6}{|c|}{ Table 3: Type of Causative Fungi } \\
\hline
\end{tabular}

The type of causative fungi were Fusarium species in $15(50.0 \%)$, Aspergillus species in $12(40.0 \%)$ and Candida species in 3(10.0).

\begin{tabular}{|c|c|c|c|}
\hline $\begin{array}{l}\text { Sl. } \\
\text { No }\end{array}$ & Time of Healing in Weeks & $\begin{array}{l}\text { No. of } \\
\text { Cases }\end{array}$ & $\%$ \\
\hline 1. & $4-6$ weeks & 4 & 13.3 \\
\hline 2. & $6-8$ weeks & 12 & 40.0 \\
\hline 3. & 8 - 10 weeks & 5 & 16.7 \\
\hline 4. & 10 - 12 weeks & 4 & 13.3 \\
\hline 5. & $\begin{array}{c}\text { Progressed to Corneal } \\
\text { Perforation after } 2 \text { - } 3 \text { weeks } \\
\text { of treatment of intracorneal and } \\
\text { intracameral Voriconazole }\end{array}$ & 5 & 16.7 \\
\hline & & 30 & 100.0 \\
\hline \multicolumn{4}{|c|}{$\begin{array}{c}\text { Table 4: Time of Healing after intracorneal } \\
\text { and intracameral voriconazole }\end{array}$} \\
\hline
\end{tabular}

The time of healing of the Fungal Corneal Ulcer after Intracorneal and Intracameral Voriconazole was $4(13.3 \%)$ in 4-6 wks., $12(40.0 \%)$ in 6 - 8 wks., $5(16.7 \%)$ in $8-10$ wks., and $4(13.3 \%)$ in $10-12$ wks.

\begin{tabular}{|c|c|c|c|c|c|}
\hline $\begin{array}{l}\text { Sl. } \\
\text { No }\end{array}$ & $\begin{array}{c}\text { Clinical } \\
\text { Outcome }\end{array}$ & Males & Females & Total & $\%$ \\
\hline 1 & $\begin{array}{c}\text { Corneal Scar } \\
\text { formation }\end{array}$ & 15 & 10 & 25 & 83.3 \\
\hline 2 & $\begin{array}{c}\text { Corneal } \\
\text { Perforations }\end{array}$ & 4 & 1 & 5 & 16.7 \\
\hline & Total & 19 & 11 & 30 & 100.0 \\
\hline
\end{tabular}

25(83.3\%) healed with Corneal scar and 5(16.7\%) progressed to corneal perforations after intracorneal and intracameral voriconazole.

\begin{tabular}{|c|c|c|c|c|c|}
\hline \multirow[b]{2}{*}{$\begin{array}{l}\text { Sl. } \\
\text { No }\end{array}$} & \multirow[b]{2}{*}{$\begin{array}{l}\text { Visual } \\
\text { Acuity }\end{array}$} & \multicolumn{2}{|c|}{ Before } & \multicolumn{2}{|c|}{ After } \\
\hline & & $\begin{array}{l}\text { No. of } \\
\text { Cases }\end{array}$ & $\%$ & $\begin{array}{l}\text { No. of } \\
\text { Cases }\end{array}$ & $\%$ \\
\hline 1. & $<3 / 60$ & 18 & 60.0 & 3 & 10.0 \\
\hline 2. & $\begin{array}{l}3 / 60- \\
<6 / 60\end{array}$ & 12 & 40.0 & 13 & 43.3 \\
\hline 3. & $\begin{array}{l}6 / 60- \\
<6 / 18\end{array}$ & 0 & 0.0 & 9 & 30.0 \\
\hline 4. & $>6 / 18$ & 0 & 0.0 & 0 & 0.0 \\
\hline \multicolumn{2}{|c|}{ Total } & 30 & 100.0 & 25 & 83.3 \\
\hline 5. & \multicolumn{3}{|c|}{$\begin{array}{c}\text { Progressed to Corneal } \\
\text { Perforation }\end{array}$} & 5 & 16.7 \\
\hline \multicolumn{4}{|c|}{ Total } & 30 & 100.0 \\
\hline
\end{tabular}

Table 6: Visual acuity before and after Intracorneal and Intracameral Voriconazole

Visual acuity was $<3 / 60$ in $18(60.0 \%)$ and $3 / 60$ to $<6 / 60$ in $12(40.0 \%)$, and $<3 / 60$ in $3(10.0 \%), 3 / 60-<6 / 60$ in $13(43.3 \%)$ and $6 / 60-<6 / 18$ in $9(30.0 \%)$ before and after the intracorneal and intracameral voriconazole respectively.

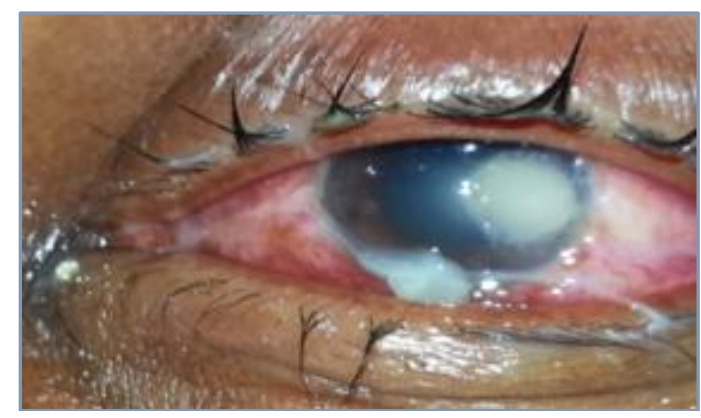

Fig. 1: Deep Keratomycosis before Intracorneal and Intracameral Voriconazole

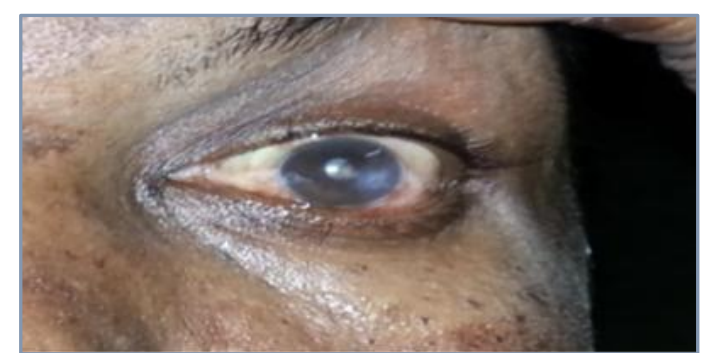

Fig. 2: Healed Keratomycosis after Intracorneal and Intracameral Voriconazole

The 25(83.3\%) cases which were healed by corneal scarring were given 1 (One) intracorneal and intracameral injection of Voriconazole. The 5(16.7\%) cases, which did not respond to 2 (Two) intracorneal and intracameral voriconazole injections, progressed to corneal perforations and were treated by therapeutic penetrating keratoplasty.

\section{DISCUSSION}

Ophthalmic mycosis is emerging as a major cause of vision loss and morbidity. Fungal keratitis is one of the major causes of ophthalmic mycosis. $(4,5)$ It is known that fungi are destroyed by a humoral and cellular host defence mechanism, but the large size of the hyphae of filamentous fungi precludes ingestion by neutrophils. Fungal hyphae tend to multiply extensively without inducing much cellular infiltration leading to a disease process that may be indolent.

Fungi can penetrate the intact Descemet membrane and enter the anterior chamber resulting in endothelial plaque and hypopyon, which is difficult to treat with antifungal agents because of their poor ocular penetration or 
bioavailability and toxicity.(6,8) Generally, prolonged and intensive topical and systemic antifungal therapy is required to eradicate the fungal infections. Contemporary antifungal drugs in the treatment of mycotic keratitis are less effective than contemporary antibacterial drugs in the treatment of bacterial keratitis. Moreover, the penetration of many antifungal drugs into the cornea is suboptimal, which makes it difficult to treat cases of deep keratomycosis. Hence, to overcome these problems targeted drug delivery to achieve adequate drug levels at the site of infection by intracorneal and intracameral injections of antifungals are being evaluated. Voriconazole has optimal activity against fungi that are resistant to amphotericin B and itraconazole. $(6,7,8)$

Our study Causative fungi were Fusarium in 50.0\%, Aspergillus in $40.0 \%$ and Candida in $10.0 \%$ correlates with the studies of Bharathi MJ, et al.(14) of Fusarium $42.82 \%$ followed by Aspergillus of $26.0 \%$. and Gopinathan U, et al.(15) of Fusarium 37.2\% followed by Aspergillus of 30.7\%. Our study vegetative matter trauma $50.0 \%$ was compared to $61.28 \%$ in Bharathi MJ, et al.(14) and of $22.97 \%$ in Suman Saha, et al.(16) Our study Age distribution of $4(13.3 \%)$ in $>10$ 20 Yrs; $5(16.7 \%)$ in $21-30$ Yrs; $4(13.3 \%)$ in $31-40$ Yrs; $6(20.0 \%)$ in $41-50$ Yrs; $5(16.7 \%)$ in $51-60$ Yrs; and $6(20.0 \%)$ in 61-70 Yrs showing higher incidence with increasing age and with $63.3 \%$ of males compared to $36.7 \%$ of females correlating with the studies of Bharathi MJ, et al.(14) Gopinathan U, et al.(15) and Suman Saha, et al.(16) So, our study and other studies show that the fungal keratitis was commonly caused by Fusarium and Aspergillus with Vegetative matter trauma in males, as they are the most working class with more exposure to risk factors due to their more outdoor activities as compared to females and common with increasing age with a significant burden of visual impairment.

In our study, the time of healing after Intracorneal and Intracameral Voriconazole was $13.3 \%$ in $4-6$ wks.; $40.0 \%$ in 6-8 wks.; $16.7 \%$ in $8-10$ wks; and $13.3 \%$ in $10-12$ wks. Visual acuity was $<3 / 60$ in $18(60.0 \%)$ and $3 / 60$ to $<6 / 60$ in $12(40.0 \%)$, and $<3 / 60$ in $3(10.0 \%), 3 / 60-<6 / 60$ in 13 $(43.3 \%)$ and $6 / 60-<6 / 18$ in $9(30.0 \%)$ before and after the intracorneal and intracameral voriconazole respectively; $83.3 \%$ healed with Corneal scar and $16.7 \%$ progressed to corneal perforations after intracorneal and intracameral voriconazole; $83.3 \%$ which were healed by corneal scarring were given 1 (One) intracorneal and intracameral injection of Voriconazole; $16.7 \%$ did not respond to 2 (Two) intracorneal and intracameral voriconazole injections, progressed to corneal perforations and were treated by Therapeutic Penetrating keratoplasty. So, in our study the intracorneal and intracameral Voriconazole helped in the resolution of the deep keratomycosis with endothelial plaque with a good visual outcome with the surgical intervention only in $16.7 \%$.

Hariprasad SM, et al.(17) reviewed over 40 clinical case reports of treatment with voriconazole and suggested that it may be used safely and effectively against a broad range of fungal pathogens. Perfect JR, et al.(18) observed that voriconazole is an effective and well tolerated treatment for refractory or less-common invasive fungal infections.

Sharma N, et al.(19) conducted a study on 12 patients and concluded that intrastromal injection of voriconazole may be used as a modality of treatment for managing cases of recalcitrant fungal keratitis. Prakash G, et al.(20) observed that targeted delivery of voriconazole by intracorneal injection may be a safe and effective way to treat cases of deep seated recalcitrant fungal keratitis responding poorly to conventional treatment modalities.

In Ganapathy Kalaiselvi, et al.(21) 25 patients with culture proven fungal keratitis, not responding to a combination of topical $5 \%$ natamycin and $1 \%$ voriconazole were treated with intrastromal voriconazole and concluded that targeted delivery of voriconazole by intrastromal injection was a safe and effective way to treat deep recalcitrant fungal keratitis.

Jain $\mathrm{V}$, et al.(22) concluded that topical therapy along with a judicious use of intrastromal administration of voriconazole may be of immense benefit in refractory fungal keratitis.

Singh PK, et al.(23) in a case report observed that intrastromal injections of voriconazole helped in early and complete resolution of the ulcers and it is a new promising therapy for fungal keratitis refractory to standard antifungal agents. So, intracorneal voriconazole was reported to be safe and effective in deep recalcitrant fungal keratitis in the studies of Namrata Sharma, et al.(19) Gaurav Prakash, et al.(20) Ganapathy Kalaiselvi, et al.(21) Jain V, et al.(22) and Singh PK, et al.(23)

Shen YC, et al.(24) conducted a retrospective, consecutive case series of 10 patients to report the therapeutic efficacy of intracameral voriconazole in the treatment of fungal endophthalmitis resulting from keratitis and concluded that intracameral voriconazole may be an effective treatment for fungal endophthalmitis contiguously spreading from keratitis. Gupta et al.(25) reported that intracameral Voriconazole injection to be a safe and effective treatment in intracameral extension following penetrating keratoplasty for fungal keratitis.

Haddad RS, et al.(26) observed that combination of intracameral and intrastromal voriconazole in the treatment of recalcitrant Acremonium fungal keratitis was cost-effective treatment in impeding the progression of keratitis.

So our study correlate with the above studies that the intracorneal and intracameral Voriconazole has a therapeutic role in the clinical resolution of the deep keratomycosis with endothelial plaque with a good visual outcome. In all cases reported in the literature so far, intracorneal and intracameral injections of antifungal agents were used as a last resort to treat cases of non-healing deep fungal keratitis not responding to conventional therapy. In our study also intracorneal and intracameral voriconazole were given to 30 patient's refractory to conventional antifungal therapy with $83.3 \%$ resolving completely and $16.7 \%$ developing corneal perforations indicating treatment failure requiring therapeutic penetrating keratoplasty, i.e. surgical intervention was required only in $16.7 \%$.

In summary, intracorneal and intracameral voriconazole injections may be effective in the treatment of deep keratomycosis. None of our patients developed any toxic effects with the drug after the injection. It was observed that judicious and timely use of intracorneal and intracameral voriconazole injections as an adjunctive therapy may be undertaken in selected patients who are unresponsive to other forms of antifungal therapy. The major advantage of this treatment modality is that it delivers the drug at the site of infection, achieving a high intracorneal and aqueous concentration, which may not be possible with topical and systemic antifungal therapy. So, a combination of Intracorneal and Intracameral voriconazole is a new promising therapy for fungal keratitis refractory to standard antifungal agents. Further studies and randomised controlled trials with larger sample size are recommended before this choice of treatment assumes a standard approach.

\section{CONCLUSIONS}

Targeted delivery of Intracorneal and Intracameral Voriconazole had a therapeutic role with a better visual routine antifungal therapy. Less number of therapeutic keratoplasties was performed in patients of deep 
keratomycosis with endothelial plaque, who received voriconazole injection intracorneally or intracamerally.

To give more number of injections and to wait for a longer time before deciding about Therapeutic Keratoplasty may be a better option to bring about healing.

\section{REFERENCES}

1. Park K. Epidemiology of Chronic Non-Communicable Diseases and conditions-Blindness. In: K Park, editor. Park's Textbook of Preventive and Social Medicine, 21 st ed. Jabalpur (MP): M/s Banarsidas Bhanot; 2011. P. 37072.

2. John $P$, Whitcher J, Srinivasan M, Madan P Upadhyay. Corneal blindness: A global perspective. Bull World Health Organ. 2001;79(3):214-221.

3. Srinivasan M. Fungal keratitis. Curr Opin Ophthalmol 2004;15:321-7.

4. Namrata Sharma, Rasik B Vajpayee. Fungal keratitis. In: Namrata Sharma and Rasik B Vajpayee, editor. Corneal ulcers Diagnosis and Management, $1^{\text {st }}$ edition. New Delhi: Jaypee Brothers Medical Publishers (p) Ltd.); 2008. P.7778.

5. Eduardo C, Alfonso, Robert H Rosa, Jr, Darlene Miller. Fungal keratitis. In: Jay $\mathrm{H}$ Krachmer, Mark J Mannis, Edward J Holland, editors. Cornea, $2^{\text {nd }}$ ed. Philadelphia: Elsevier Mosby, An affiliate of Elsevier Inc.; 2005.p.110103.

6. Yoon KC, Jeong IY, Im SK, Chae HJ, Yang SY. Therapeutic effect of intracameral amphotericin $\mathrm{B}$ injection in the treatment of fungal keratitis. Cornea 2007;26:814-818.

7. Yilmaz S, Ture M, Maden A. Efficacy of intracameral amphotericin B injection in the management of refractory keratomycosis and endophthalmitis. Cornea 2007;26:398-402.

8. Kuriakose T, Kothari M, Paul P, Jacob P, Thomas R. Intracameral amphotericin $\mathrm{B}$ injection in the management of deep keratomycosis. Cornea 2002;21:653-656.

9. Garcia-Valenzuela E, Song CD. Intrastromal injection of amphothericin B for recurrent fungal keratitis and endophthalmitis. Arch Ophthalmol 2005;123:1721-1723.

10. Marangon FB, Milller D, Giaconi JA, Alphonso EC. In vitro investigation of voriconazole susceptibility for keratitis and endophthalmitis fungal pathogens; Am J Ophthalmol 2004 May;137(5):820-5.

11. Lalitha P, Shapiro BL, Srinivasan M, et al. Antimicrobial susceptibility of Fusarium, Aspergillus, and other filamentous fungi isolated from keratitis. Arch Ophthalmol 2007;125:789-793.

12. Gao H, Pennesi M, Shah K, et al. Intravitreal voriconazole: an electroretinographic and histopathologic study. Arch Ophthalmol 2004;122:1687-1692.

13. Nehemy MB, Vasconcelos-Santos DV, Torqueti-Costa L, Magalhaes EP. Chronic endophthalmitis due to Verticillium species after cataract surgery treated (Or managed) with parsplana vitrectomy and oral and intravitreal voriconazole. Retina 2006;26:225-227.
14. Bharathi MJ, Ramakrishnan R, Vasu S, Meenakshi R, Palaniappan R. Epidemiological characteristics and laboratory diagnosis of fungal keratitis. A three-year study. Indian J Ophthalmol 2003;51:315-21.

15. Gopinathan $U$, Garg $P$, Fernandes $M$, Sharma S, Athmanathan S, Rao GN. The epidemiological features and laboratory results of fungal keratitis: a 10 -year review at a referral eye care centre in South India. Cornea 2002 Aug; 21(6):555-9.

16. Saha S, Banerjee D, Khetan A and Sengupta J. Epidemiological profile of fungal keratitis in urban population of West Bengal, India. Oman J Ophthalmol 2009 Sep-Dec; 2(3): 114-118.

17. Hariprasad SM, Mieler WF, Lin TK, Sponsel WE, JR Graybill l. Voriconazole in the treatment of fungal eye infections: a review of current literature. Br J Ophthalmol 26 April 2008;92:871-878.

18. Perfect JR, Marr KA, Walsh TJ, Greenberg RN, DuPont B, de la Torre-Cisneros J, Just-Nübling G, Schlamm HT, Lutsar I, Espinel-Ingroff A, Johnson El; Voriconazole treatment for less-common, emerging or refractory fungal infections; Clin Infect Dis. 2003 May 1;36(9):1122-31.

19. Namrata Sharma, Prakashchand Agarwal, Rajesh Sinha, Jeewan S Titiyal, Thirumurthy Velpandian, Rasik B Vajpayee. Evaluation of intrastromal voriconazole injection in recalcitrant deep fungal keratitis: case series. Br J Ophthalmol 2011;95:1735-1737.

20. Prakash G, Sharma N, Goel M, Jeewan S Titiyal, Rasik B Vajpayee. Evaluation of Intrastromal Injection of Voriconazole as a Therapeutic Adjunctive for the Management of Deep Recalcitrant Fungal Keratitis. Am J Ophthalmol 2008 Jul 24;146(1):56-59.

21. Ganapathy Kalaiselvi, Sivananda Narayana, Tiruvengada Krishnan, Sabyasachi Sengupta. Intrastromal voriconazole for deep recalcitrant fungal keratitis: a case series $\mathrm{Br}$ J Ophthalmol 2015;99:195-198.

22. Jain V, Borse N, Shome D, et al. Recalcitrant fungal tunnel infection treated with intrastromal injection of voriconazole; Int Ophthalmol 2010 Dec; 30(6):723-5.

23. Singh PK, et al; Case report - intrastromal voriconazle in deep resistant fungal keratitis; Rajasthan Journal of Ophthalmol; 2011.

24. Shen YC1, Wang CY, Tsai HY, Lee HN. Intracameral voriconazole injection in the treatment of fungal endophthalmitis resulting from keratitis. Am J Ophthalmol. 2010 Jun; 149(6):916-21.

25. Gupta, Gaurav MD; Feder, Robert S MD; Lyon, Alice T MD. Fungal Keratitis with Intracameral Extension Following Penetrating Keratoplasty. Cornea: September 2009;28:930-2.

26. Randa S Haddad and Georges M El-Mollayess. Combination of Intracameral and Intrastromal Voriconazole in the Treatment of Recalcitrant Acremonium Fungal Keratitis. Middle East Afr J Ophthalmol. 2012 Apr-Jun; 19(2):265-268. 